\title{
Fluorometer for Screening of Doxorubicin in Perfusate Solution and Tissue with Solid-Phase Microextraction Chemical Biopsy Sampling
}

Victor Galievsky and Janusz Pawliszyn*

Department of Chemistry, University of Waterloo, Waterloo, Ontario, N2L 3G1, Canada

* Corresponding author, janusz@uwaterloo.ca.

Table of Contents

1. Chemical structure of DOX .............................................. S-2

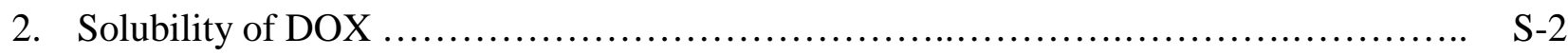

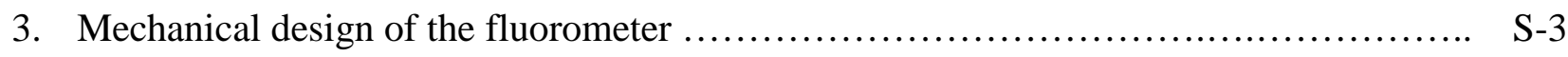

4. SEM images of the C18 fiber ............................................ S-4

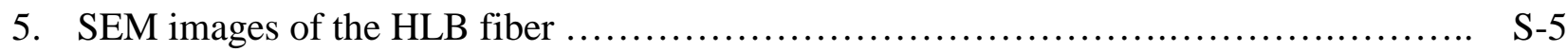

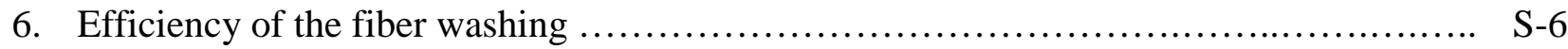

7. Dependence of the background signal on the DOX concentration ................... S-6

8. Dependences of the detected signals on fiber rotation ............................. S-7

9. Effect of extraction time on the extraction efficiency of C8-SCX fibers ................ S-8

10. Effect of extraction time on the extraction efficiency of HLB fibers .................. S-8

11. Dependence of the fluorescence signal on the storage time $\ldots \ldots \ldots \ldots \ldots \ldots \ldots \ldots \ldots \ldots . . . .6$

12. Calibration curves for DOX/PBS with C18 fibers ............................... S-9

13. Calibration curves for DOX/PBS with HLB fibers ............................ S-10

14. Parameters of calibration curves for DOX with C8-SCX fibers ..................... S-10 


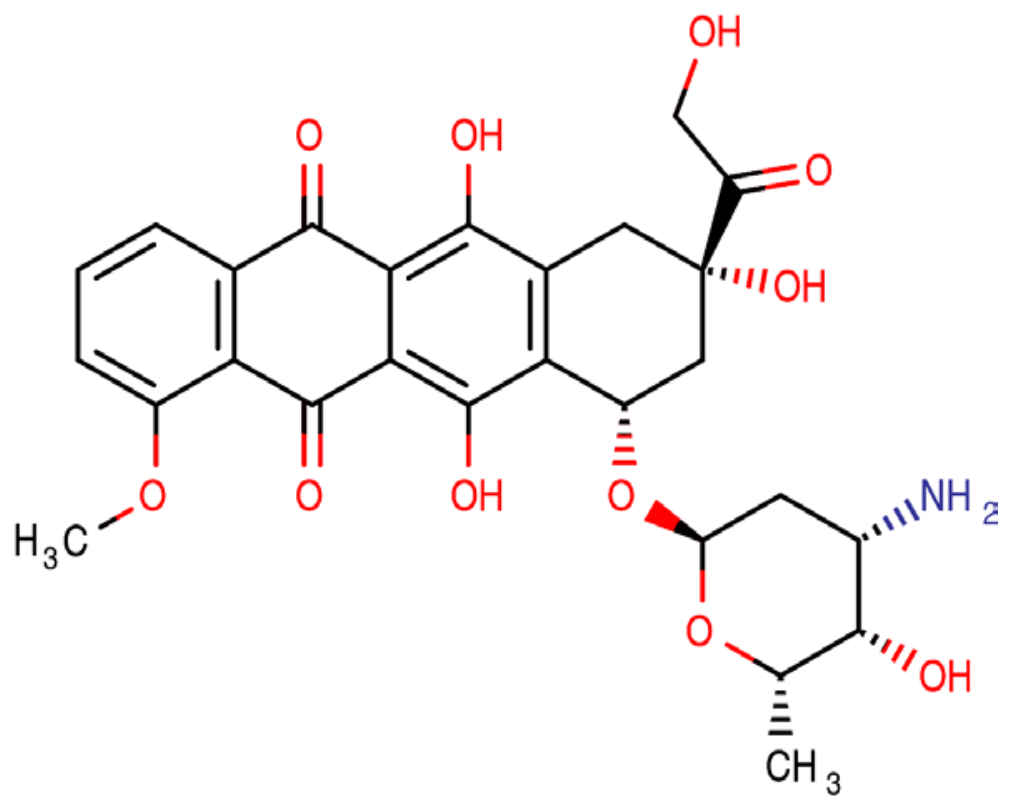

Figure S1. Chemical structure of doxorubicin (DOX).

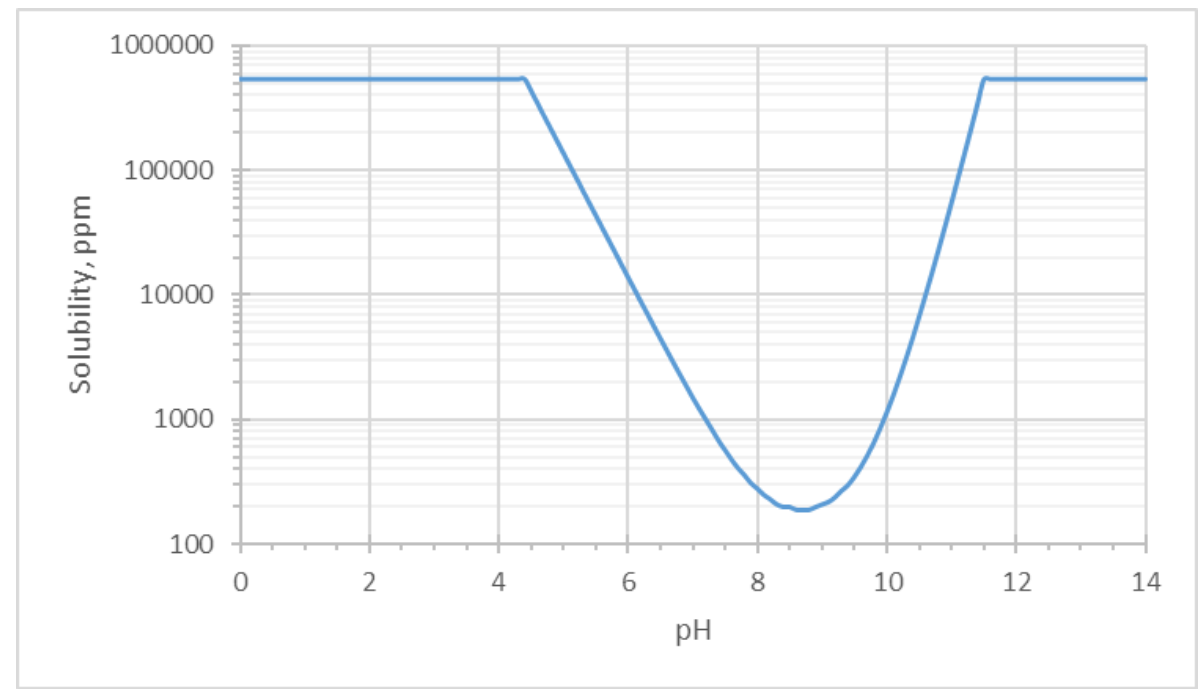

Figure S2. Calculated solubility of DOX as function of $\mathrm{pH}$ value of the water solution. Data obtained from website: https://chemicalize.com. 


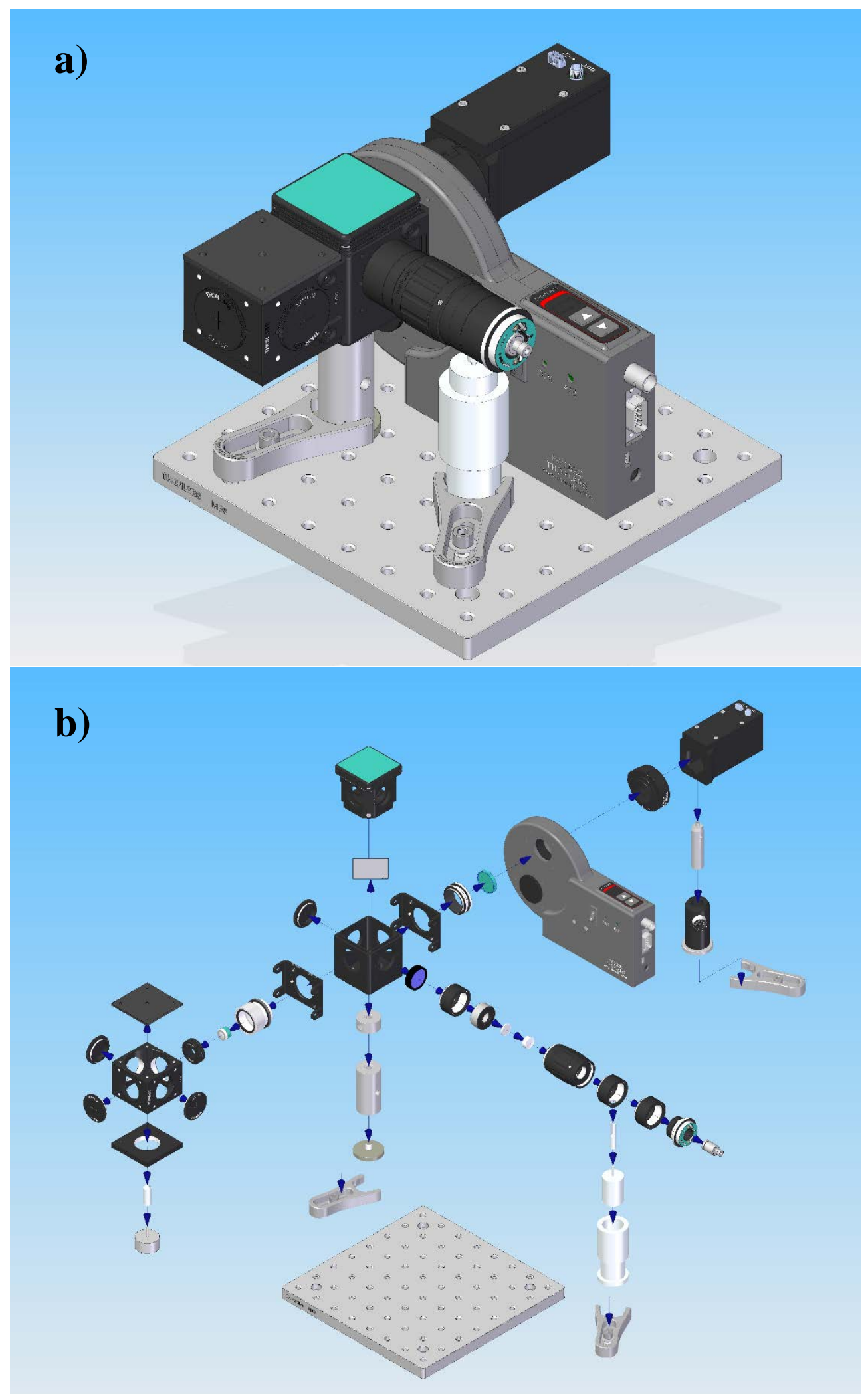

Figure S3. Mechanical design of the fluorometer: a) assembled view, b) exploded view. 


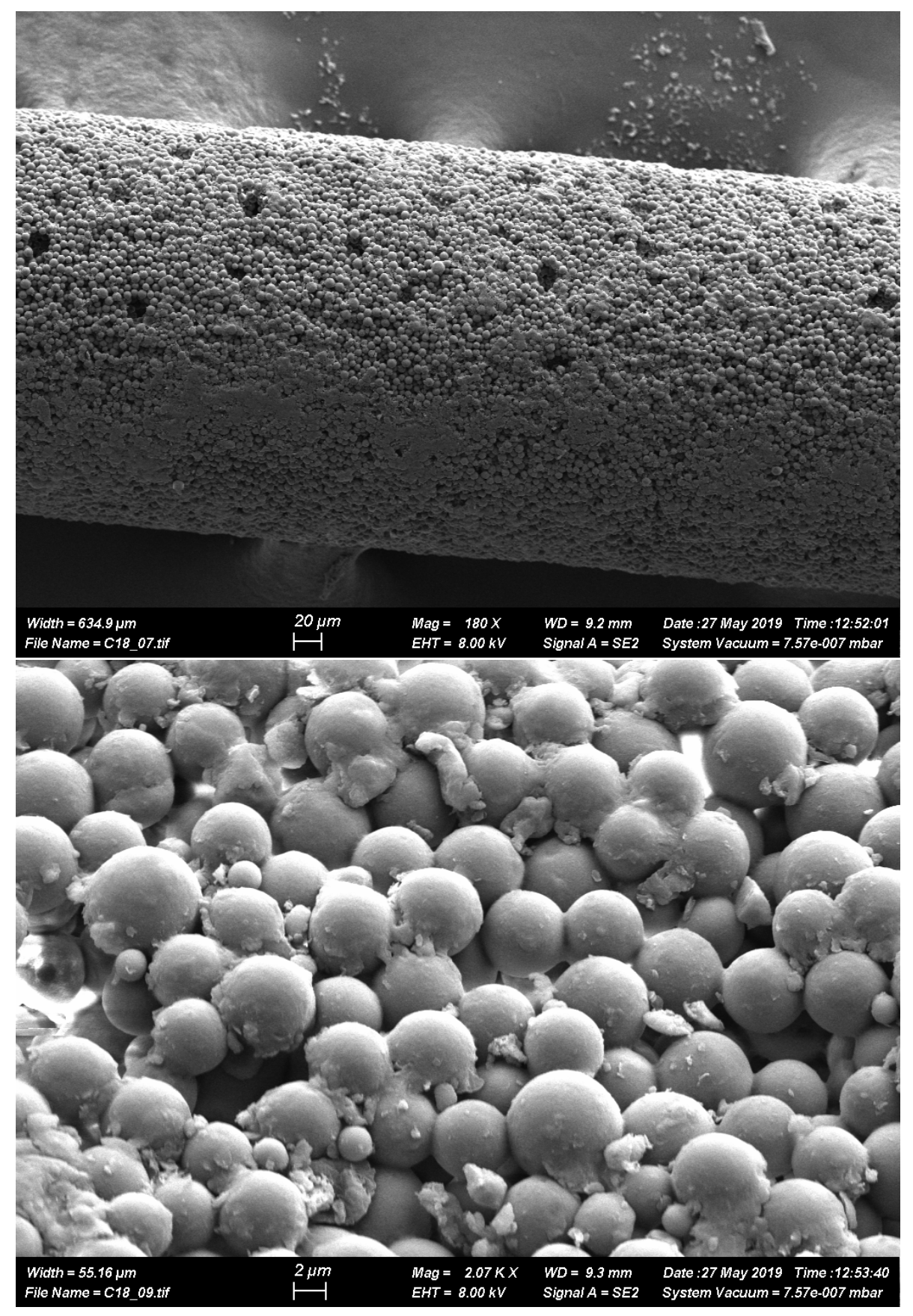

Figure S4. SEM images of the C18 fiber. 


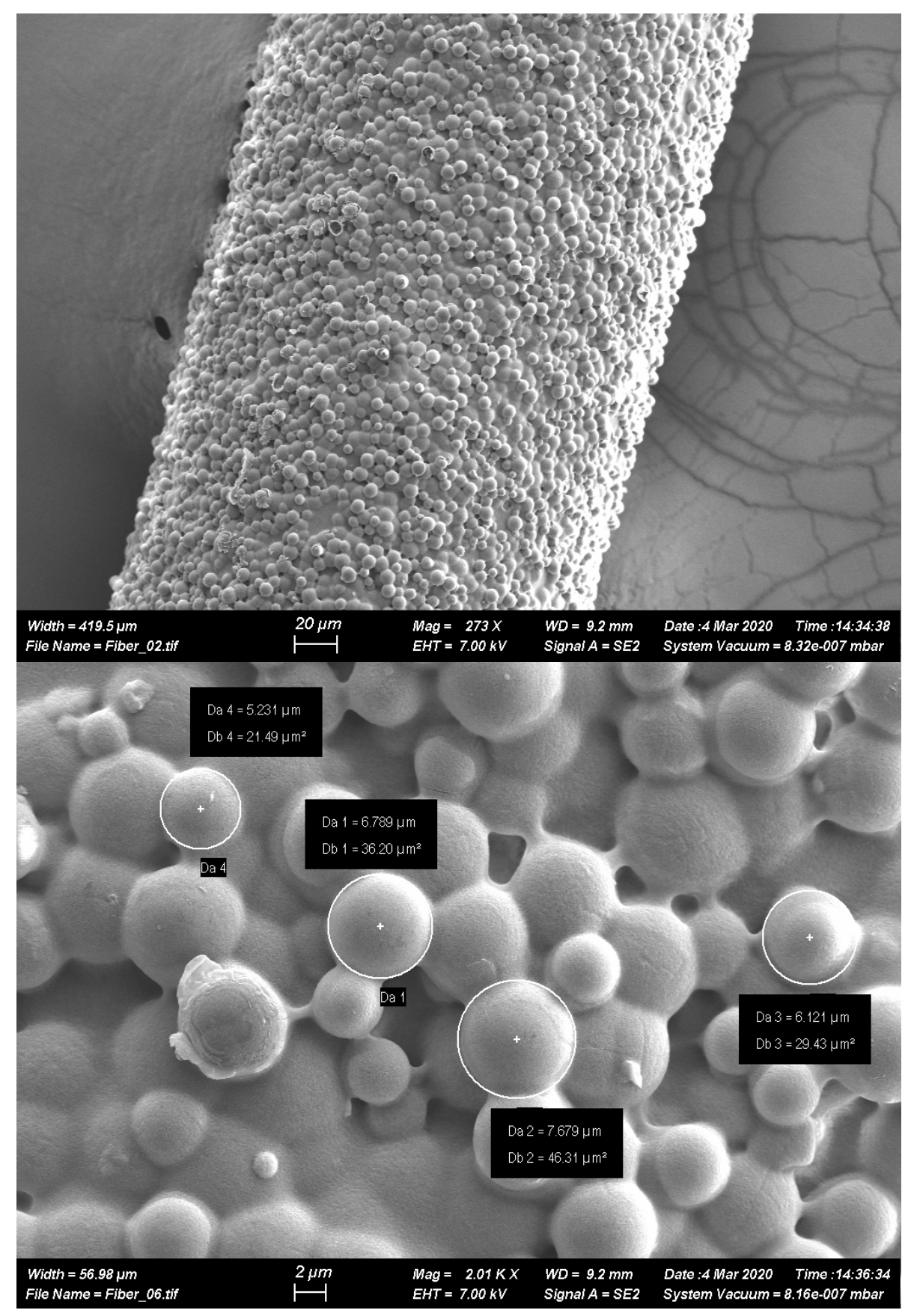

Figure S5. SEM images of the HLB fiber. 


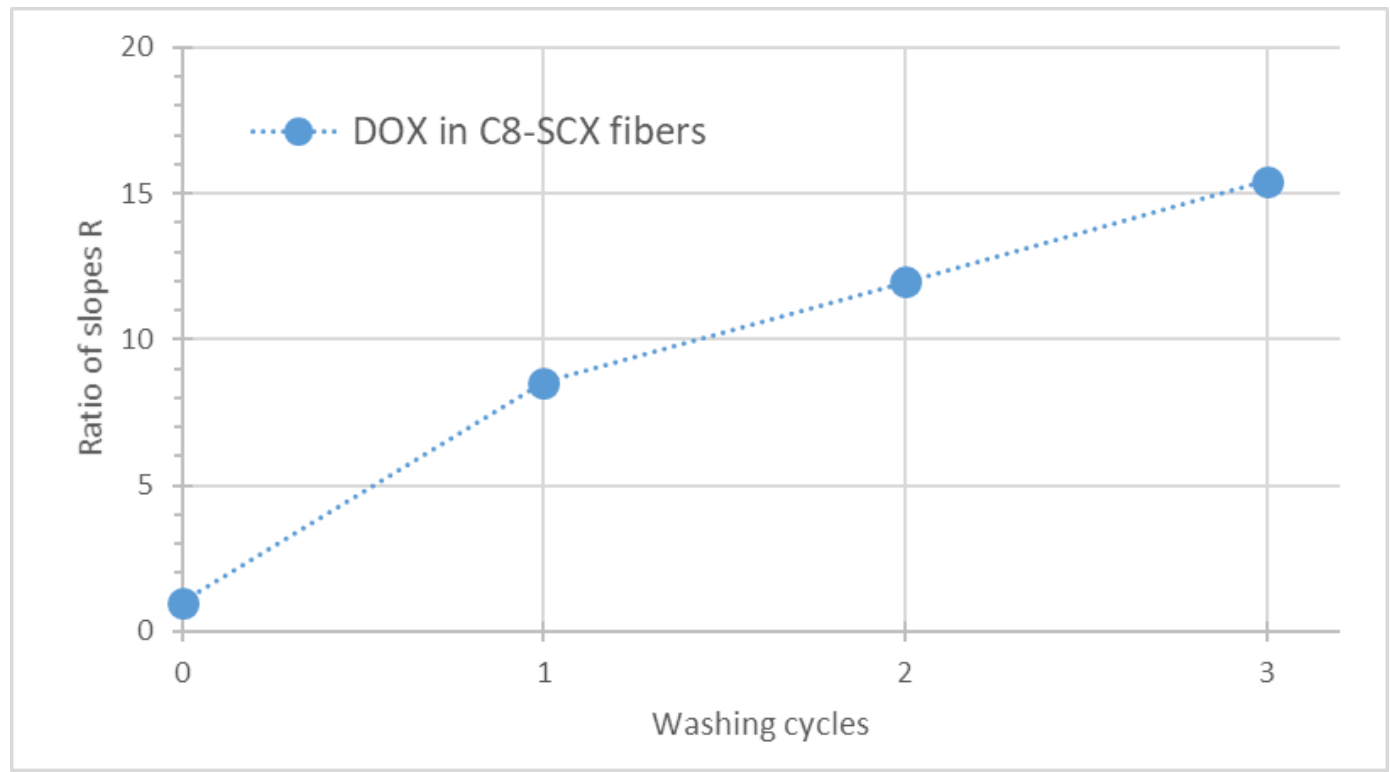

Figure S6. Dependence of the ratio $\mathrm{R}=\mathrm{a}_{0} / \mathrm{a}_{\mathrm{n}}$ on the number of fiber washing cycles. The value of $\mathrm{a}_{0}$ is the slope of calibration curve for DOX in PBS measured using C8-SCX fibers (see the insert in Figure 5). The value of $a_{n}$ represents the slope of calibration curve, measured after washing the fibers $n$ times. SPME fibers were washed in a mixture of MeOH/IP/ACN/water (10:5:5:2, v/v) with the addition of formic acid $(1 \%, \mathrm{v} / \mathrm{v})$ for 1 hour at $1500 \mathrm{rpm}$ agitation.

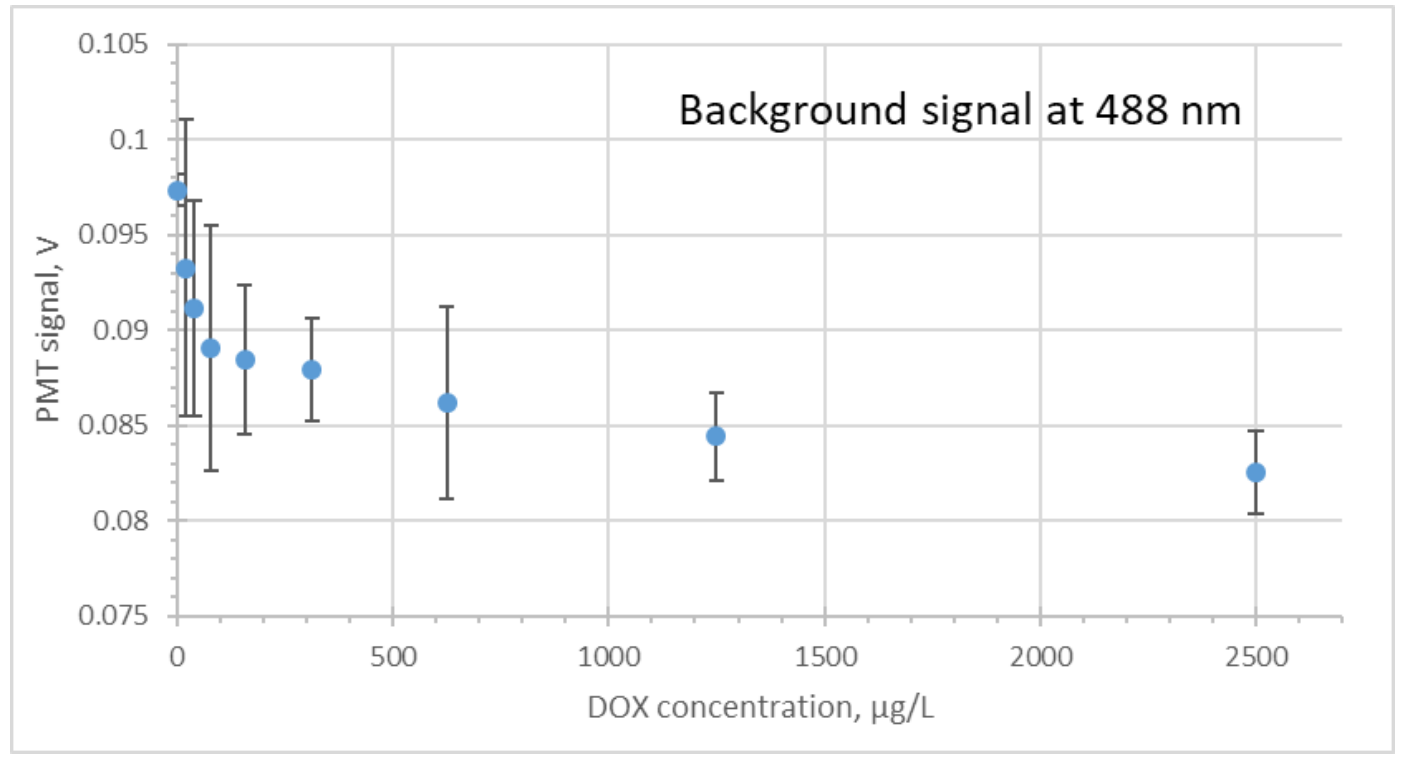

Figure S7. Dependence of the background signal measured at $488 \mathrm{~nm}$ on the DOX concentration in PBS for the C8-SCX fiber. Error bars show the standard deviation $(n=3)$. 


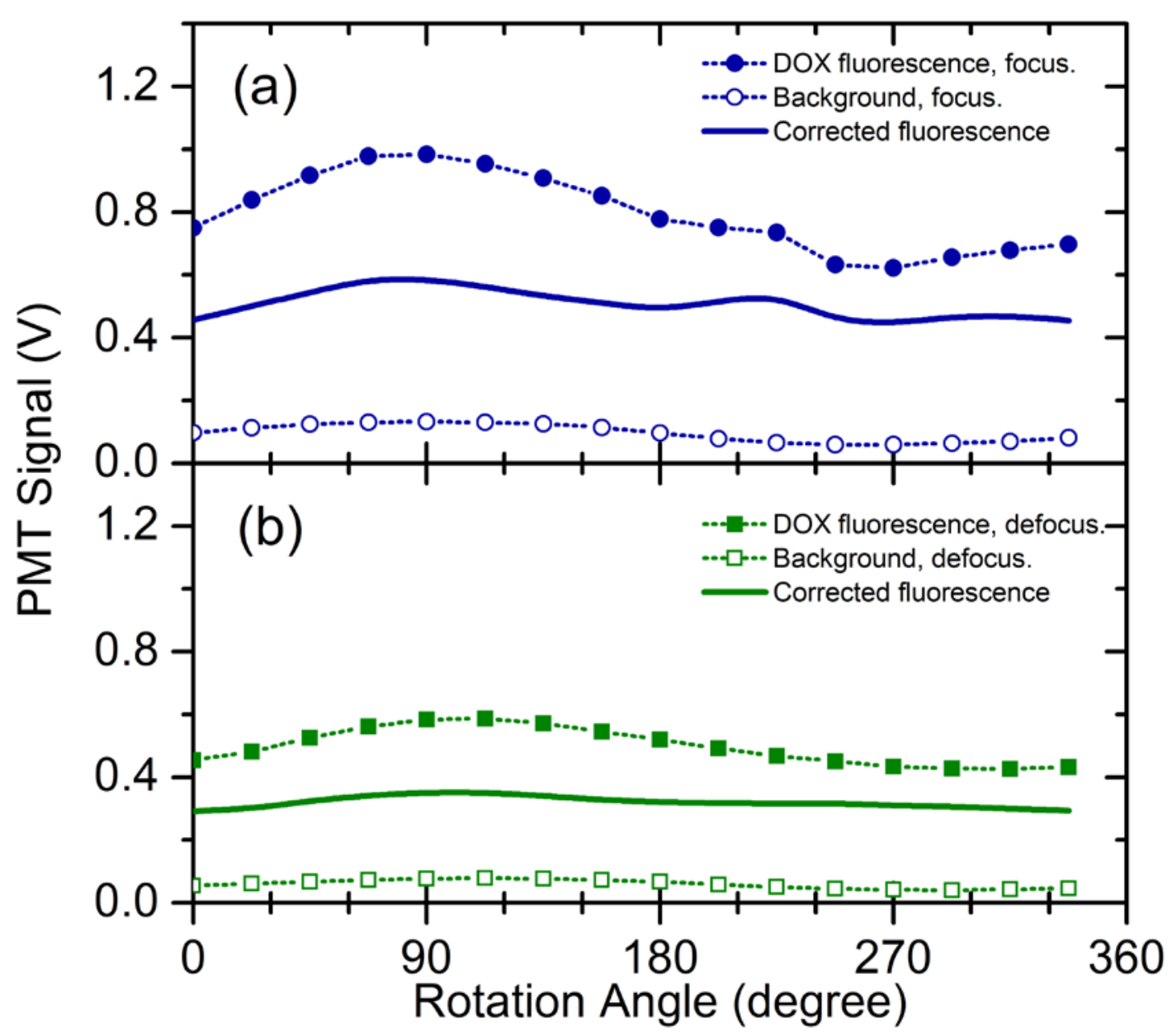

Figure S8. Dependences of the DOX fluorescence and background signals on fiber rotation for focused (a) and defocused (b) excitation beams. The solid lines represent the fluorescence corrected for the background using eq. 1 and $k=2.8$. DOX was applied to the fiber via a 30-min extraction from PBS with a DOX concentration of $0.625 \mathrm{mg} \mathrm{L}^{-1}$. Since the dark signal was generally small, it has not been presented for the sake of simplifying the visual. The relative standard deviations (RSD) of the fluorescence signal were $15.6 \%$ and $11.8 \%$ for the focused and defocused excitations, respectively. The RSD of the corrected signal decreased to $7.8 \%$ and $4.4 \%$ for the focused and defocused excitations, respectively. 


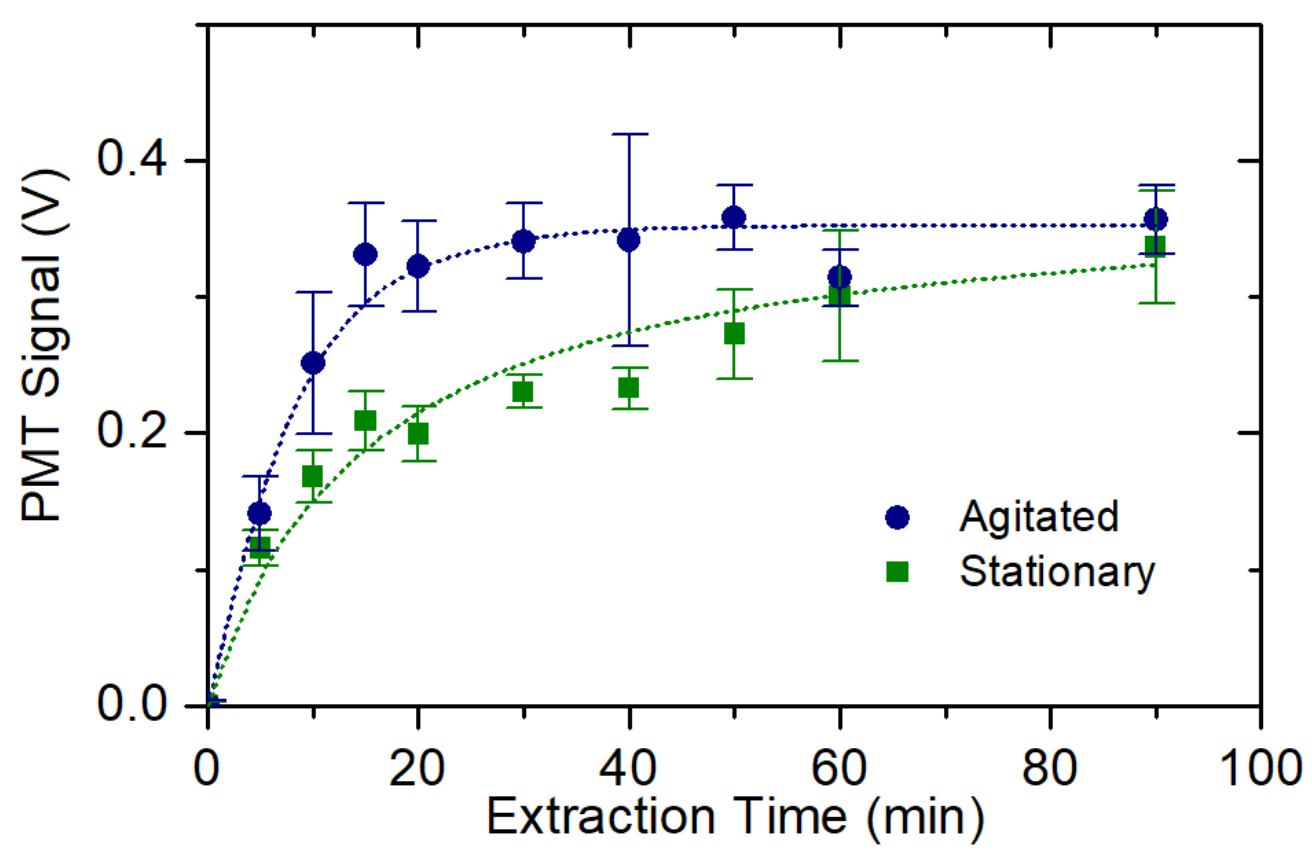

Figure S9. Effect of extraction time on the extraction efficiency of C8-SCX fibers under agitation at 1500 rpm and in a stationary state. Error bars show the standard deviation $(n=3)$. The lines represent fitting by a saturation-type exponential function. DOX was concentrated in the PBS at $0.625 \mathrm{mg} \mathrm{L}^{-1}$, and the temperature was $21^{\circ} \mathrm{C}$.

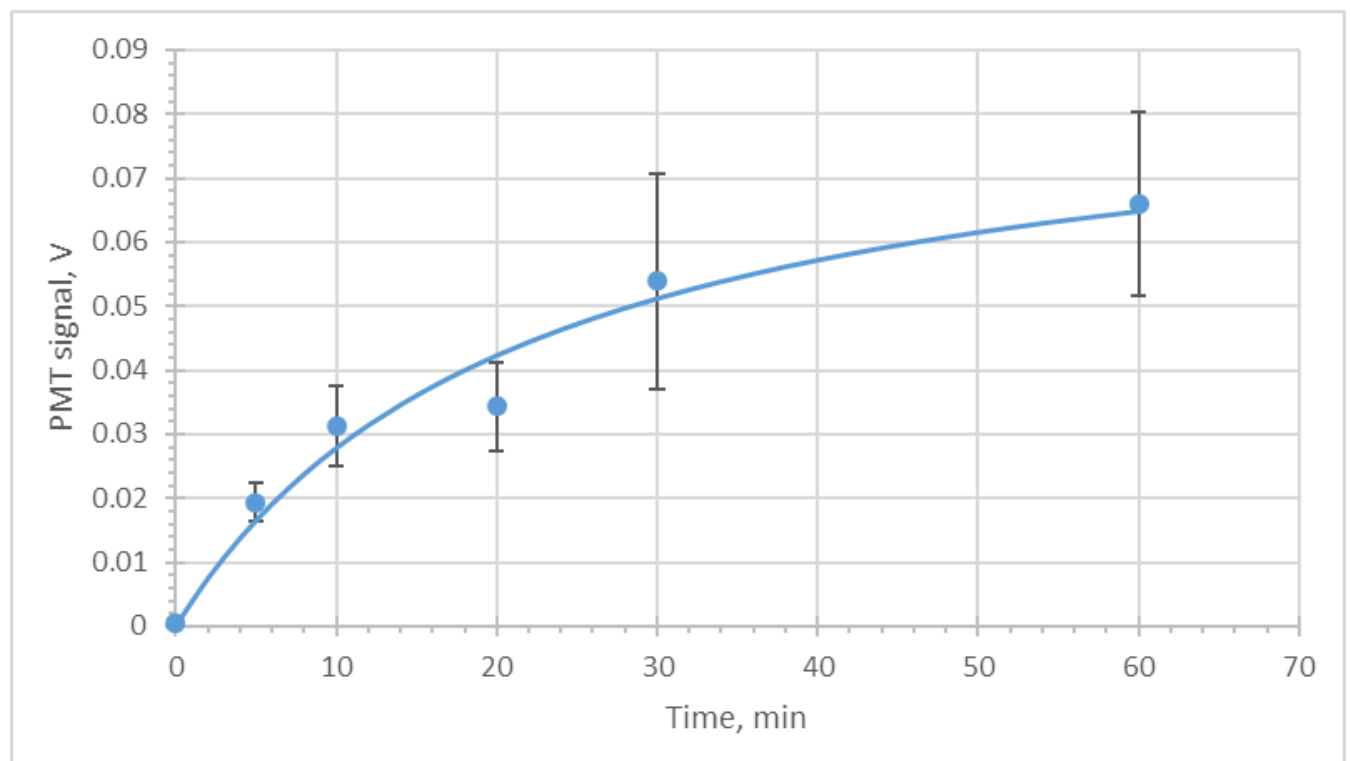

Figure S10. Effect of extraction time on the extraction efficiency of HLB fibers under agitation at 1500 $\mathrm{rpm}$. The DOX concentration was $0.625 \mathrm{mg} \mathrm{L}^{-1}$ in PBS, the vial volume was $1 \mathrm{ml}$, and the temperature was $21^{\circ} \mathrm{C}$. Error bars show the standard deviation $(\mathrm{n}=3)$. The line represents fitting by a saturation-type exponential function. 


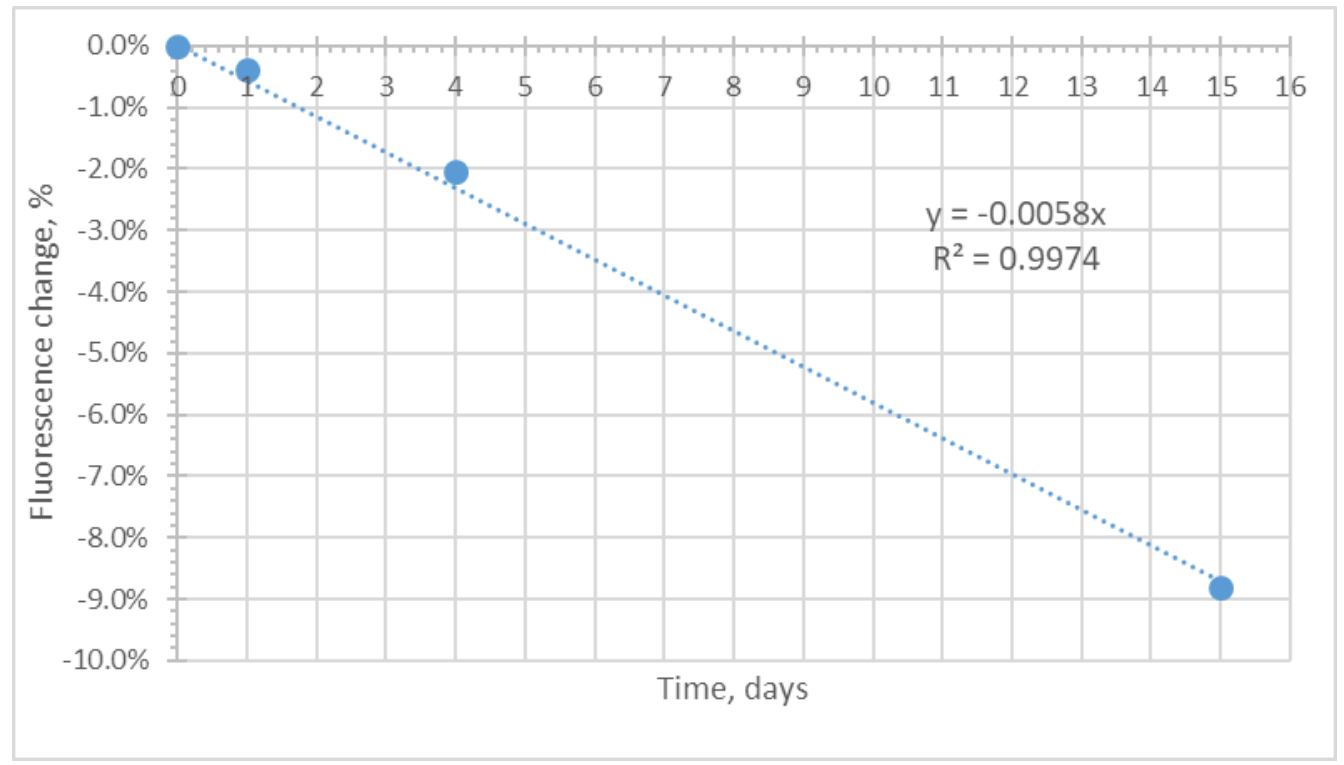

Figure S11. Dependence of the fluorescence signal of DOX on the storage time of the C8-SCX fiber in the dark at room temperature (about $21^{\circ} \mathrm{C}$ ).

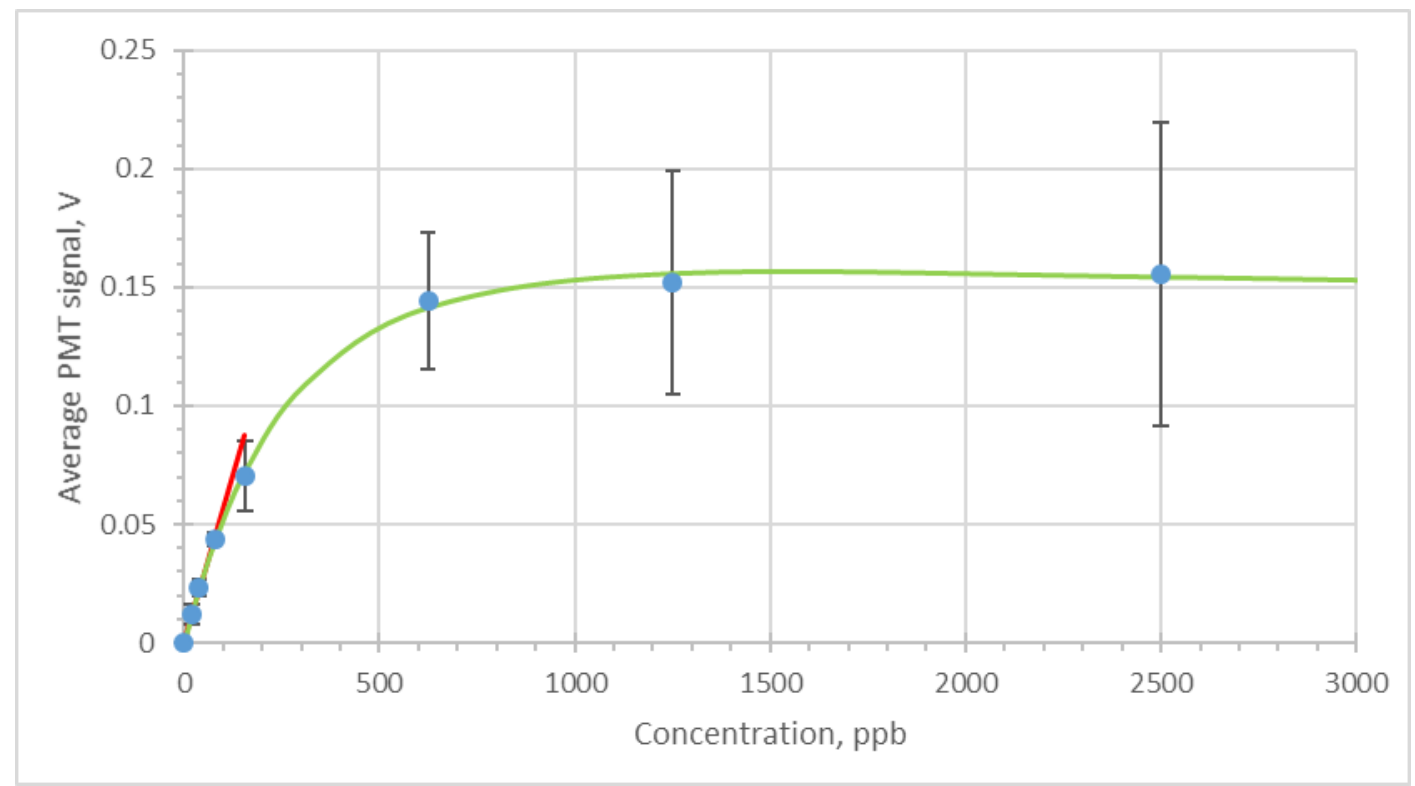

Figure S12. Calibration curves for DOX/PBS with C18 fibers. The line was obtained by fitting the data to eqs. 1-4. The parameters $\alpha, \gamma$, and $\mathrm{K}$ were found to be $(1.2 \pm 0.1) \times 10^{6} \mathrm{~V} \mathrm{~m}^{2} \mathrm{~mol}^{-1},(6.3 \pm 1.4) \times 10^{-7} \mathrm{~mol} \mathrm{~m}^{-2}$, and $520 \pm 180 \mathrm{~m}^{3} \mathrm{~mol}^{-1}$, respectively. The slope of the fitting line was $(5.6 \pm 0.2) \times 10^{-4} \mathrm{~V} \mathrm{mg}^{-1} \mathrm{~L}$. Error bars show the standard deviation $(\mathrm{n}=3)$. 


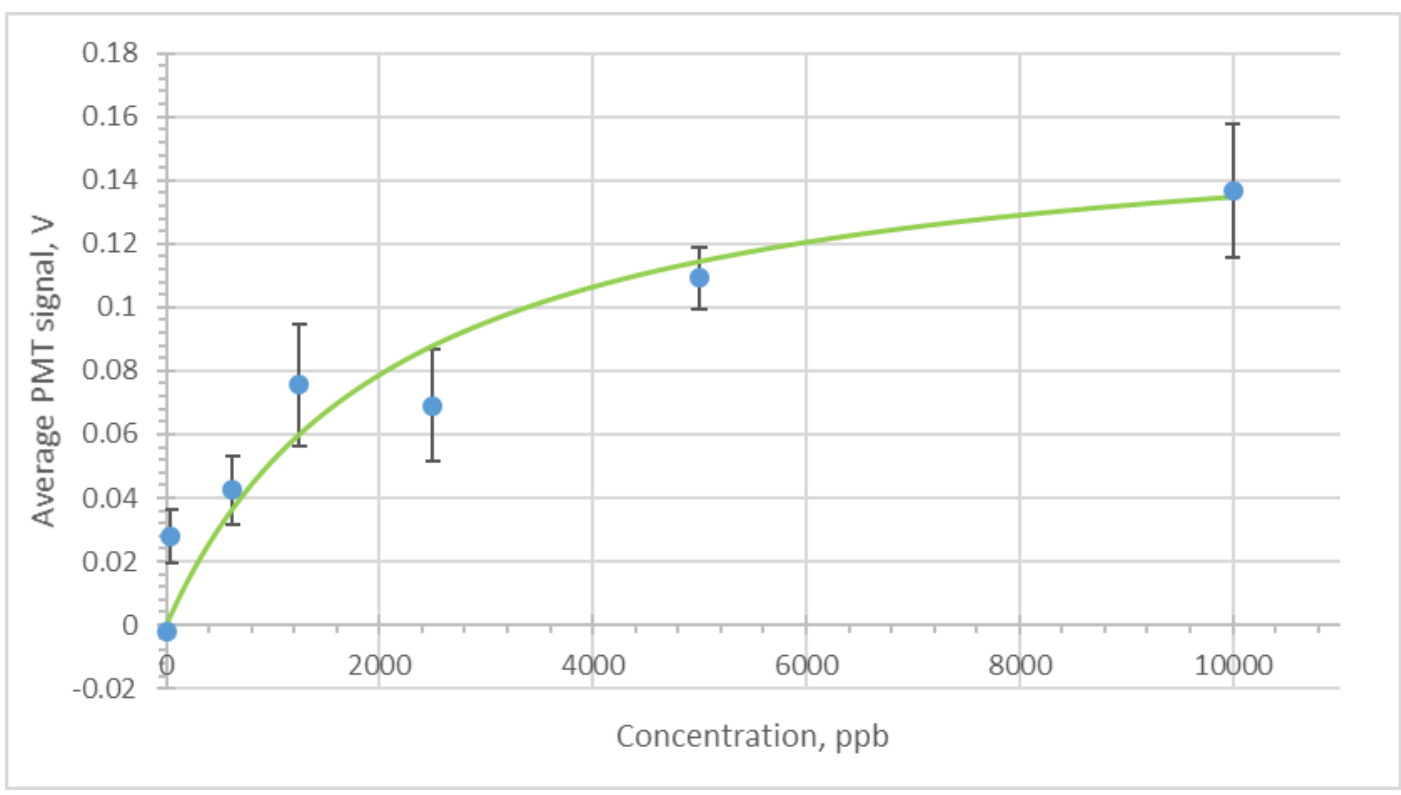

Figure S13. Calibration curves for DOX/PBS with HLB fibers. The line was obtained by fitting the data to eqs. 1-4. The parameters $\alpha, \gamma$, and $\mathrm{K}$ were found to be $(3.7 \pm 3.7) \times 10^{6} \mathrm{~V} \mathrm{~m}^{2} \mathrm{~mol}^{-1},(5.1 \pm 5.1) \times 10^{-8} \mathrm{~mol} \mathrm{~m}^{-2}$, and $(230 \pm 230) \mathrm{m}^{3} \mathrm{~mol}^{-1}$, respectively.

Table S1. Parameters of calibration curves to determine DOX concentration in C8-SCX fiber

\begin{tabular}{|c|c|c|c|c|c|c|c|c|c|c|}
\hline \multirow[t]{2}{*}{ Matrix } & \multirow[t]{2}{*}{$\begin{array}{l}\text { Linear range } \\
\left(\mu g \mathrm{~L}^{-1}\right)\end{array}$} & \multicolumn{2}{|c|}{$\begin{array}{l}\text { Linear equation, }^{\mathrm{a}} \\
\mathrm{y}=\mathrm{a}_{1} \mathrm{x}+\mathrm{a}_{0}\end{array}$} & \multirow[t]{2}{*}{$\begin{array}{l}\text { Correlation } \\
\text { coefficient }\end{array}$} & \multirow{2}{*}{$\begin{array}{l}\text { Non-linear } \\
\text { range } \\
\left(\mu \mathrm{g} \mathrm{L}^{-1}\right)\end{array}$} & \multicolumn{5}{|c|}{$\begin{array}{l}\text { Quaternary polynomial, }{ }^{a} \\
y=b_{4} x^{4}+b_{3} x^{3}+b_{2} x^{2}+b_{1} x+b_{0}\end{array}$} \\
\hline & & $\mathrm{a}_{1}$ & $\mathrm{a}_{0}$ & & & $\mathrm{~b}_{4}$ & $\mathrm{~b}_{3}$ & $\mathrm{~b}_{2}$ & $\mathrm{~b}_{1}$ & $\mathrm{~b}_{0}$ \\
\hline Perfusate & $100-625$ & 6370 & -24.5 & 0.994 & $100-5000$ & 2524650 & -1195510 & 183435 & -2262 & 42.6 \\
\hline Tissue & $3700-10000$ & $8.8 \times 10^{5}$ & 0 & 0.959 & - & - & - & - & - & - \\
\hline
\end{tabular}

${ }^{\mathrm{a}} \mathrm{x}$ : PMT signal (V); y: concentration $\left(\mu \mathrm{g} \mathrm{mL}{ }^{-1}\right)$

A reversed fit of concentration $C$ (y-axis) vs measured signal V ( $\mathrm{x}$-axis) was used for non-linear fitting. The fitting concentration as a function of measured signal allows us to avoid the need to solve a cubic or quaternary equation when the calibration equation is solved for $\mathrm{C}$. 